\title{
The Effects of Oral Administration of Croton penduliflorus Seed Oil and Medroxy Progesterone Acetate on Fasting Blood Sugar, Lipid and Haematology of Pregnant Rabbits
}

\author{
${ }^{1}$ S.A. Ojokuku, ${ }^{2}$ O.S. Odesanmi and ${ }^{2}$ O.A. Magbagbeola \\ ${ }^{1}$ Department of Chemical Science, School of Science, \\ Yaba College of Technology, Nigeria \\ ${ }^{2}$ Department of Biochemistry, College of Medicine, \\ University of Lagos, Lagos, Nigeria
}

\begin{abstract}
Croton penduliflorus, Hutch ubiquitous to Southern Nigeria is used in the treatment of diverse diseases. This study investigated the effects of oral administration of the petroleum ether extract on lipid, fasting blood sugar and haematological parameters of pregnant rabbits. Croton penduliflorus Seed Oil (CPSO) was prepared by soxhlet extraction of shelled, oven dried, ground seed sample with $40-60^{\circ} \mathrm{C}$ petroleum ether. Twenty five, acclimatized pregnant rabbits weighing 1-1.6 $\mathrm{kg}$ and at mid gestation were randomly allocated into 5 groups. Animals in group 1 served as the control while groups 2-4 received $50,100,150 \mathrm{mg} \mathrm{kg}^{-1}$ body weight oral dose of CPSO for 10 consecutive days. Animals in group 5 received one intramuscular injection of $2.73 \mathrm{mg} \mathrm{kg}^{-1}$ of medroxyprogesterone acetate. Withdrawal of treatment was followed by $18 \mathrm{~h}$ fast followed sacrifice after anesthesia. Fasting blood samples were collected from all the groups by cardiac puncture and analyzed for blood sugar, haematological and lipids profiles. Results were analyzed using student's t-test and ANOVA. Medroxyprogesterone acetate significantly lowered $(\mathrm{p}<0.05)$ the fasting serum glucose, total cholesterol, PCV and MCV. CPSO at $50 \mathrm{mg} \mathrm{kg}^{-1}$ body weight elicited a similar but more pronounced response causing a highly significant $(\mathrm{p}<0.01)$ lowering of haemoglobin, total cholesterol. Croton penduliflorus is hypocholesterolemic but may predispose to anaemia.
\end{abstract}

Key words: Croton penduliflorus, medroxy progesterone acetate, hypocholesterolemic, disease, treatment, Lagos, Nigeria

\section{INTRODUCTION}

The use of plants as medicine to cure or prevent illness or maintain well being is due to their phytochemical constituents and this date back to the early century as it is found in every society irrespective of its level of development and sophistication (Odugbemi, 2006; Yakubu et al., 2007). Medicinal plant extracts are now sources of direct therapeutic agents or as raw material base for the elaboration of more complex semi-synthetic compounds. Croton penduliflorus Hutch belongs to the family of Euphorbiacaea, it is commonly known as Turk's Cap (Yoruba Aworoso, Igbo Ogwuaki or Aki Ozara) thought to originate from Malaysia is a tropical evergreen plant widely distributed in southern part of Nigeria. It is credited with antimicrobial, antivenom, antiparalytical, rubefacient and anti-tumor potencies. It is also used in the treatment of cancer, constipation, diabetes, digestive problems, dysentery, external wounds, fever, hypercholesterolemia, hypertension, inflammation, intestinal worms, malaria, pain, ulcers, weight-lost and as contraceptive (Salatino et al., 2007; Odugbemi, 2008; Bablola, 2009). It forms a major component of herbal contraceptives, abortifacient and anti-fibroid concoctions used in the local treatment of fibroids (Adjanohoun et al., 1991; Odesanmi et al., 2006). Croton seed and its oil have been used in treatment of wide range of disorders in the past both in pregnant and non pregnant individuals (Oyesola et al., 2009). Medroxyprogesterone acetate (Depo provera), an orthodox injectable contraceptive is used in the management of symptomatic uterine fibroids (Venkatachalam et al., 2004). The earlier report of the

Corresponding Author: S.A Ojokuku, Department of Chemical Science, School of Science, Yaba College of Technology, Nigeria 
effects of oral administration Croton penduliflorus seed oil put the kidney and liver under stress (Ojokuku et al., 2010). However, this study is part of an on-going research designed to investigate the effects of oral administration of Croton pendilflorus seed oil and Medroxy progesterone acetate on haematological parameters, lipids profile and fasting blood sugar in pregnant rabbits as animal model.

\section{MATERIALS AND METHODS}

Sourcing of materials (Plant material): Croton penduliflorus seeds were purchased from the herbal market in Mushin Local Government area of Lagos in 2008. The sample was identified and authenticated in department of Botany and Microbiological of the University of Lagos. A voucher specimen was deposited at the herbarium.

Medroxy progesterone acetate (Depo provera) $150 \mathrm{mg} \mathrm{mL}^{-1}$ (NAFDAC Reg. No 04- 2310) was obtained from the University Community Pharmacy, CMUL, Idi-Araba, Lagos. All other chemicals were of analytical grade.

Preparation of plant seed extract: Croton penduliflorus seed samples were sorted, cleaned and the hard outer seed coat removed. The seeds were then oven-dried at $45^{\circ} \mathrm{C}$ for 3 days and ground to powder with the Christy-Norris Laboratory Hammer Mill. The powdered seed sample was kept in an airtight container at room temperature until extracted. About $500 \mathrm{~g}$ of powdered seeds were subjected to soxhlet extraction with $2.5 \mathrm{~L}$ of 40-60 petroleum ether into exhaustion $(5 \mathrm{~h})$. The liquid extract was pooled, concentrated in a rotatory evaporator under reduced pressure and controlled temperature and oven-dried at $40^{\circ} \mathrm{C}$. The dried oil was stored in amber bottle and refrigerated until utilized. The percentage yield was calculated. Weighed portions of the stock seed oil were reconstituted into calculated graded doses of 50, 100 and $150 \mathrm{mg} / \mathrm{kg} / \mathrm{mL}$, respectively using $5 \%$ tween 20 as vehicle.

Experimental animals and study design: Investigation using experimental animals (Dutch-white rabbits) was conducted in accordance with the internationally accepted principle for laboratory animal use and care $(\mathrm{NIH}$ Publication No. 85-23, 1985). Mature females and males Dutch-white rabbits in the weight range $1-1.6 \mathrm{~kg}$ were obtained from the laboratory animal centre of the College of Medicine, University of Lagos, Idi-Araba and Nigerian
Institute of Medical Research Yaba. The animals were housed in metabolic cages with males separated from females in the metabolic laboratory under ambient temperature and $12 \mathrm{~h}$ light and dark periodicity. They were fed commercial rabbit pellets (Niemeth livestock Feeds, Ltd. Ikeja) and water ad libitum and allowed to acclimatize for 4 weeks. The females were observed for the next 7 days for signs of heat as marked by restlessness and swollen vulva. Labeled rabbits on heat were introduced into the male cages for mating and then returned to their former cages once mating was confirmed. The date of mating was recorded. Successful service and pregnancy were confirmed by easy loss of hair with a gentle pull and the feel of marble-shaped lumps under the belly 14 days after mating (mid-gestation). Twenty five rabbits out of the pregnant female weighing, 1-1.6 kg were selected and randomly allocated to 5 groups of 5 rabbits/group such that the difference in average weight did not exceed $5 \mathrm{~g}$. Rabbits in group 1 served as control and were each given daily oral dose of 5\% tween 20 (vehicle) only via catheter. Groups 2-4 received doses of 50,100 and $150 \mathrm{mg} \mathrm{kg}^{-1}$ body weight of Croton Penduliflorus Seed Oil (CPSO) respectively for 10 consecutive days from day 15 of pregnancy (midgestation). Rabbits in group 5 were each given intramuscular injection of the pharmacological dose ( $2.73 \mathrm{mg} \mathrm{mL}^{-1}$ ) of Depo provera once at mid-gestation. All animals were weighed twice weekly and allowed feed and water ad libitum throughout period of assay. Treatment was terminated on day 24 of gestation. All groups were fasted overnight $(18 \mathrm{~h})$ then sacrificed after anesthesia with diethyl ether. Blood samples were collected from each animal via cardiac puncture into heparinized and non heparinnized sample bottles.

Heamatological analysis: The heparininzed blood sample were analyzed for White Blood Cell (WBC), Red Blood Cell (RBC), Heamoglobin (Hb), Parked Cell Volume (PCV), Mean Corpuscular Volume (MCV), Mean Corpuscular Heamoglobin $(\mathrm{MCH})$, Mean Corpuscular Heamoglobin Concentration (MCHC) using methods described by Dacie and Lewis (1994).

Lipids and serum glucose analysis: The blood sample in the non heparinized bottle was allowed to clot at room temperature. The clot was removed and the fluid centrifuged at $2,500 \mathrm{~g}$ for $10 \mathrm{~min}$ to obtain the fasting serum. The serum for each group was pooled and stored in the biofreezer until analyzed.

The serum samples from each group were subjected to glucose, triacylglycerides, high-density lipo protein 
and cholesterol were determined using Randox Laboratory kit reagents. Low Density Lipoprotein (LDL) cholesterol was determined by differential subtraction of the sum of the cholesterol fractions from the total cholesterol (Tietz, 1990; Yakubu et al., 2006).

Statistical analysis: All results were analyzed using students t-test and ANOVA with the aid of SPSS (ver. 15) software package. The level of statistical significance was taken as $\mathrm{p}<0.05$.

\section{RESULTS AND DISCUSSION}

Oral administration of graded doses of CPSO did not have any significant change on the serum triglyceride and HDL-Cholesterol in all groups including Depo provera when compared to the control (Table 1). There was decrease in serum cholesterol $(\mathrm{p}<0.05)$ in all the groups including Depo provera after the administration. In addition there was significant decreased $(\mathrm{p}>0.05)$ in LDL-Cholesterol in all the groups excluding Depo provera group when compared to the control. On fasting blood sugar, oral administration of graded doses of CPSO did not have any significant effect on serum glucose in all the groups when compared to the control (Table 2). On haematology, there was a significant decreased $(\mathrm{p}<0.05)$ in the parked cell volume of the animals administered with CSPO compared to the control (Table 3). However, heamoglobin levels increased significantly after the initial dose of CPSO, this was sustained at higher doses. The red blood cell count decreased significantly $(\mathrm{p}<0.05)$ at lower dose but at higher doses the value went up significantly. The white blood cell count decreased at lower dose of CSPO and in Depo provera groups but normalizes at higher doses. The mean cell volume decrease at higher doses of CSPO and in the Depo group compared to the control.

The results of the present study suggest hypocholesterolemic effects; this trend was observed in a study carried on ethanol extract of Croton pendifflorus seed on pregnant rabbits (Odesanmi et al., 2006). It has also been reported that extracts of Croton cajucara leaves showed significant reductions in the serum total cholesterol, low-density lipoprotein cholesterol and triglyceride levels as well as a significant elevation in the $\mathrm{HDL} /$ total cholesterol ratio in treated rats compared with the control group (Salatino et al., 2007). This may account for the traditional therapeutic use of C. cajucara species in the Amazon region for the control of hyperlipidemy and associated pathologies (Salatino et al., 2007). It has been documented that the reduction of serum total cholesterol and Low Density Lipoprotein (LDL) Cholesterol is a primary risk factor for prevention of cardiovascular disease (Edijala et al., 2005). HDL functions in the transport of cholesterol away from the peripheral tissues to the liver thus preventing the genesis of atherosclerosis. The observed non significant change in the level of $\mathrm{HDL}$ further points to the cardiac protective activity of CPSO. Further investigations are needed to identify the hypolipidemic active principles and elucidate their mechanism of action. Glucose concentration did not change significantly in all groups including medroxy progesterone acetate after the administration however it has been reported that Croton cajucara showed

Table 1: The effects of oral administration of varied doses of Croton pendulilforus seed oil and intramuscular injection of medroxy progesterone acetate on serum lipids profile in pregnant rabbits ${ }^{1}$

\begin{tabular}{|c|c|c|c|c|c|c|}
\hline Group/treatments & Dose (mg kg${ }^{-1}$ B.wt) & Triglyceride $\left(\mathrm{mg} \mathrm{dL}^{-1}\right)$ & Cholesterol $\left(\mathrm{mg} \mathrm{dL}^{-1}\right)$ & HDL-Chol. (mg dL ${ }^{-1}$ ) & LDL-Chol. (mg dL ${ }^{-1}$ ) & HDL/LDL ratio \\
\hline Control & - & $1.07 \pm 0.25$ & $8.80 \pm 1.55$ & $1.23 \pm 0.35$ & $7.20 \pm 3.10$ & $0.17 \pm 0.11$ \\
\hline Depo provera & 2.73 & $0.90 \pm 0.01$ & $6.06 \pm 0.30^{*}$ & $1.15 \pm 0.03$ & $4.63 \pm 0.15$ & $0.25 \pm 0.20$ \\
\hline \multicolumn{7}{|l|}{ CPSO } \\
\hline $\mathrm{i}$ & 50.00 & $1.62 \pm 0.96$ & $1.47 \pm 0.35^{\text {*** }}$ & $0.43 \pm 0.15$ & $0.33 \pm 0.60^{* * *}$ & $1.30 \pm 0.25^{* * *}$ \\
\hline ii & 100.00 & $1.03 \pm 0.22$ & $3.18 \pm 0.25^{* * *}$ & $1.63 \pm 0.85$ & $1.37 \pm 0.31^{* * *}$ & $1.19 \pm 2.74^{* * *}$ \\
\hline$\underline{\text { iii }}$ & 150.00 & $1.23 \pm 0.25$ & $1.80 \pm 0.20^{* * *}$ & $0.67 \pm 0.25$ & $0.60 \pm 0.30^{* * *}$ & $1.12 \pm 0.83^{* *}$ \\
\hline
\end{tabular}

${ }^{1}$ Value represents Mean \pm SD for 5 rabbits and triplicate determination; ${ }^{*} \mathrm{p}<0.05$, $* * \mathrm{p}<0.01$ are considered significantly different compared to control

Table 2: The effect of oral administration of varied doses of Croton pendulilfonis seed oil and intramuscular injection of medroxy progesterone acetate on serum glucose in pregnant rabbits ${ }^{1}$

\begin{tabular}{lcc}
\hline Group/treatments & Dose $\left(\mathrm{mg} \mathrm{kg}^{-1} \mathrm{B.wt}\right)$ & $\left.\mathrm{Glucose}^{(\mathrm{mg} \mathrm{dL}} \mathrm{dL}^{-1}\right)$ \\
\hline Control & - & $6.41 \pm 0.35$ \\
Depo provera & 2.73 & $4.37 \pm 1.40$ \\
CPSO & 50.00 & $5.30 \pm 1.10$ \\
i & 100.00 & $5.86 \pm 0.50$ \\
ii & 150.00 & $7.27 \pm 1.25$ \\
iii & & \\
${ }^{1}$ Value represents Mean \pm SD for 5 rabbits and triplicate determination; * $\mathrm{p}<0.05, * * * 0.01$ are considered significantly different compared to control
\end{tabular}


Int. J. Trop. Med., 6 (2): 35-38, 2011

Table 3: The effects of oral administration of varied doses of Croton pendulilforus seed oil and intramuscular injection of Medroxy progesterone acetate on haematological profile in pregnant rabbits ${ }^{1}$

\begin{tabular}{|c|c|c|c|c|c|c|c|c|}
\hline Group/treatments & Dose (mg kg${ }^{-1}$ B.wt) & PCV (\%) & $\mathrm{HB}(\mathrm{g} \%)$ & $\mathrm{RBC} \mathrm{mm^{3 } \times 1 0}$ & $\mathrm{WBC} \mathrm{mm}^{3} \times 10$ & $\mathrm{MCHC}(\mathrm{g} \%)$ & $\mathrm{MCV} \mathrm{m}^{3} \times 10$ & $\mathrm{MCH} \mathrm{Pg} \times 10$ \\
\hline Control & - & $45.00 \pm 2.0$ & $7.00 \pm 1.00$ & $3.3 \pm 0.20$ & $3.77 \pm 0.32$ & $15.50 \pm 1.52$ & $13.70 \pm 1.45$ & $2.13 \pm 0.45$ \\
\hline $\begin{array}{l}\text { Depo provera } \\
\text { CPSO }\end{array}$ & 2.73 & $30.00^{\text {*** }}$ & $7.00 \pm 1.00$ & $3.5 \pm 0.20$ & $3.05 \pm 0.05^{*}$ & $23.30 \pm 3.30^{*}$ & $8.60 \pm 0.50^{* * *}$ & $2.00 \pm 0.20$ \\
\hline (i) & 50.00 & $34.00 \pm 1^{* * * *}$ & $11.00 \pm 1.00^{* * * *}$ & $2.9 \pm 0.10^{*}$ & $3.05 \pm 0.05^{*}$ & $32.33 \pm 2.00^{* * *}$ & $11.67 \pm 0.76$ & $3.80 \pm 0.50^{\text {*** }}$ \\
\hline (ii) & 100.00 & $38.00 \pm 1 *$ & $8.00 \pm 1.00$ & $4.6 \pm 0.10^{* * *}$ & $3.77 \pm 0.32$ & $21.10 \pm 3.26$ & $8.27 \pm 0.06^{* * *}$ & $1.73 \pm 0.25$ \\
\hline (iii) & 150.00 & $40.00 \pm 1 *$ & $11.00 \pm 1.01^{* * *}$ & $4.1 \pm 0.10^{* * *}$ & $4.20 \pm 0.20$ & $29.20 \pm 1.65^{* *}$ & $9.8 \pm 0.000^{*}$ & $2.70 \pm 0.30$ \\
\hline
\end{tabular}

${ }^{1}$ Value represents Mean \pm SD for 5 rabbits and triplicate determination; ${ }^{*} \mathrm{p}<0.05$, *** $<0.01$ are considered significantly different compared to control. PCV: Parked Cell Volume, HB: Heamoglobin, RBC: Red Blood Cell, WBC: White Blood Cell, MCHC: Mean Corpuscular Heamoglobin Concentration, MCV: Mean Corpuscular Volume

hypoglycemic effect in alloxan-induced diabetics but not in normal rats (Salatino et al., 2007). The decreased in the PCV of treated animal may have caused aneamia in the animals.

\section{CONCLUSION}

Croton penduliflorus seed oil and Medroxy progesterone acetate caused hypocholesterolemic effects and may predispose to aneamia.

\section{ACKNOWLEDGEMENTS}

The researchers are grateful to Messrs. A.B, Ojo and O. Olakunle of the laboratory animals' centre of the college of Medicine, University of Lagos for their assistance in handling of the rabbits used for this study.

\section{REFERENCES}

Adjanohoun, E., M.R.A. Ahiyi, L.A. Assi, K. Dramane and J.A. Eewude et al., 1991. Traditional medicine and pharmacopoeia: Contribution to ethnobotanical and Organization of African Unity/Scientific Technical and Research Commission, pp: 420.

Bablola, A.K., 2009. An examination of the usage of herbal contraceptives and abortifacients in Lagos State, Nigeria. Ethnobotanical Leaflets, 13: 140-146.

Dacie, J.V. and S.M. Lewis, 1994. Practical Haematology. 8th Edn., Longman Group Ltd., Hong Kong, pp: 49-82.

Edijala, J.K., S.O. Asagba, G.E. Eriyamremu and U. Atomatofa, 2005. Comparative effects of garden egg fruit, oat and apple on serum lipid profile in rats fed a high cholesterol diet. Pak. J. Nutr., 4: 245-249.

NIH Publication No. 85-23, 1985. Respect for life. National Institute of Environmental Health Sciences-NIEHS. http://www.niehs.nih.gov/oc/factsheets/wrl/studyb gn.htm.
Odesanmi, O.S., G.M. Saibu, S.A. Ojokuku, A.T. Faremi, R.I. Bakare and A.F. Banjo, 2006. Comparative Metabolic and Histophatological Effects of Croton penduliflorus (A Herbal Abortifacient) and Depo Provera in Non-Pregnant and Pregnant Dutch-White Rabbits. In: Traditional and Modern Health Systems in Nigeria, Falola, T. and M. Heaton (Eds.). Africa World Press, Eritrea, pp: 130-146.

Odugbemi, T., 2006. Outlines and Pictures of Medicinal Plants from Nigeria. University of Lagos Press, Nigeria, ISBN: 978-38235-9-0, pp: 283.

Odugbemi, T., 2008. A Textbook of Medicinal plants from Nigeria. University of Lagos Press, Nigeria, ISBN: 978-978-48712-9-7, pp: 588.

Ojokuku, S.A., O.S. Odesanmi and O.A. Magbagbeola, 2010. The effects of oral administration of Croton penduliflorus seed oil and Depo provera on liver and kidney functions of pregnant Dutch-white rabbits. Int. J. Biol. Chem. Sci., 4: 424-431.

Oyesola, T.O., F.S. Oluwole and O.A. Oyesola, 2009. Effects of Croton pendliflous methanolic extract on intestinal enzymes and protein content in pregnant rats. Res. J. Med. Plant, 3: 141-145.

Salatino, A., M.L.F. Salatino and G. Negri, 2007. Traditional uses, chemistry and pharmacology of Croton species (Euphorbiaceae). J. Braz. Chem. Soc., 18: 11-13.

Tietz, N.W., 1990. Clinical Guide to Laboratory Test. In: Fundamentals of Clinical Chemistry, Tiez, N.W. (Ed.). W.B. Saunders, Philadelphia.

Venkatachalam, S., J.S. Bagratee and J. Moodley, 2004. Medical management of uterine fibroids with medroxyprogesterone acetate (Depo Provera): A pilot study. J. Obstetrics Gynecol., 24: 798-800.

Yakubu, M.T., A.A. Adesokan and M.A. Akanji, 2006. Biochemical changes in the liver, kidney and serum of rat following chronic administration of cimetidine. Afr. J. Biomed. Res., 9: 213-218.

Yakubu, M.T., M.A. Akanji and A.T. Oladiji, 2007. Male sexual dysfunction and methods used in assessing medicinal plants with aphrodisiac potentials. Pharmacog. Rev., 1: 49-56. 